\title{
Um olhar sobre o patrimônio e a cultura judaica em Santa Maria
}

\author{
Una mirada sobre el patrimonio y la cultura judía en Santa María \\ A look at heritage and Jewish culture in Santa Maria
}

\author{
Márcia Della Flora Cortes ${ }^{1}$ \\ Marcele Della Flora Cortes ${ }^{2}$ \\ Michele Moraes Lopes ${ }^{3}$
}

\begin{abstract}
Resumo
O presente artigo pretende contribuir para a preservação da memória e identidade judaica recuperando a história e a cultura representada pelas tradições e elementos que compõe espaços sociais. Nesse sentido, entende-se que para preservar a memória de uma sociedade, é imprescindível manter as condições mínimas de sobrevivência, abrangidas, tanto no meio ambiente, quanto em seu saber. Em 1904, cerca de 38 famílias chegaram ao Brasil para habitar o que seria a primeira colônia judaica do país, a Colônia Philippson, localizada em Itaara e que nos últimos anos resguarda uma herança que muito sofre pelo esquecimento e descaso. Dessa maneira, o conhecer, o fazer e o admirar são intrínsecos ao ato de identificar, preservar e valorizar para que a cultura se torne um legado reconhecido como patrimônio histórico, representante da cultura material de diferentes épocas, e imaterial em referência aos rituais religiosos, hábitos e costumes. Como metodologia realizou-se uma pesquisa bibliográfica, uma entrevista com o israelita Amiel Jairo e elaborou-se um inventário, onde propriedades são analisadas a partir de elementos que enriquecem a nossa história e memória. Conclui-se que o patrimônio é o resultado de um processo de construção social que para manter-se na memória da sociedade precisa ser preservado, lembrado, identificado e reconhecido por todos como parte da cultura local.
\end{abstract}

Palavras-Chave: Patrimônio; Cultura Judaica; Preservação; Memória.

\section{Resumen}

El presente artículo pretende contribuir a la preservación de la memoria e identidad judía recuperando la historia y la cultura representada por las tradiciones y elementos que componen los espacios sociales. En ese sentido, se entiende que para preservar la memoria de una sociedad, es imprescindible mantener las condiciones mínimas de supervivencia, cubiertas, tanto en el medio ambiente, como en su saber. En 1904, cerca de 38 familias llegaron a Brasil para habitar lo que sería la primera colonia judía del país, la Colonia Philippson, ubicada en Itaara y que en los últimos años resguarda una herencia que mucho sufre por el olvido y la negligencia. De esta manera, el conocer, el hacer y el admirar son intrínsecos al acto de identificar, preservar y valorar para que la cultura se convierta en un legado reconocido como patrimonio histórico, destacando su importancia material como representante estético de distintas épocas, e inmaterial en referencia a los rituales religiosos, hábitos y costumbres. Como metodología se realizó una investigación bibliográfica, una entrevista con el israelí Amiel Jairo y se elaboró un inventario, donde cada propiedad será analizada a partir de elementos que enriquecen nuestra historia y memoria. Se concluye que el patrimonio es el resultado de un proceso de construcción histórico y social que para mantenerse en la memoria de la sociedad necesita ser preservado, recordado, identificado y reconocido por todos como parte de la cultura local.

Palabras clave: Patrimonio; Cultura judía; Preservación; Memoria.

\footnotetext{
${ }^{1}$ Doutoranda em Memória Social e Patrimônio Cultural pela Universidade Federal de Pelotas; RS; Brasil; marciadfc@yahoo.com.br

${ }^{2}$ Mestre em Patrimônio Cultural pela Universidade Federal de Santa Maria, RS; Brasil, marcelecortes@yahoo.com.br

${ }^{3}$ Mestre em Patrimônio Cultural pela Universidade Federal de Santa Maria; RS; Brasil, michele.lopes@iffarroupilha.edu.br
} 


\begin{abstract}
The present article aims to contribute to the preservation of the Jewish identity and memory, recovering its history and its culture. it is undeniable that, in order to preserve the memory of a society, it is essential to maintain the minimum conditions of survival, both in the environment and in its knowledge. In 1904, around 38 families came to Brazil to form what would become the first Jewish colony of the country, called Philippson Colony, located in Itaara and which in recent years preserves an inheritance that has been oblivion and neglect. Identifying, preserving and valuing are essentials so that this culture becomes a legacy recognized as historical patrimony, highlighting its importance as an aesthetic representative of different times, religious rituals, habits and customs. The methodology was to carried out a bibliographical research, an interview with the Israeli Amiel Jairo and to organise an inventory, where each element will be analysed bringing ways to enrich our history and memory. It is concluded that heritage is the result of a process of historical and social construction that to keep in the memory of society needs to be preserved, remembered, identified and recognized by all as part of the local culture
\end{abstract}

Keywords: Heritage; Jewish Culture; Preservation; Memory.

\title{
1. Introdução
}

A longa e sofrida história dos israelenses na Palestina motivou muitos judeus a buscarem um novo país onde pudessem reconstruir suas vidas e viver em família com mais tranqüilidade, dignidade e paz.

Diante de tantos percalços, partiram para o mundo, entretanto, surgiam novos conflitos e em decorrência novas migrações. Os judeus ocuparam diferentes regiões em pequenas comunidades e embora não tivessem um estado delimitado e próprio, eram considerados uma nação que possuía fortes tradições e assim buscavam conservar sua identidade cultural através da língua, religião e até mesmo costumes, e por vezes, desagradando outras etnias.

Em 1904, cerca de 38 famílias chegaram ao Brasil para habitar o que seria a primeira colônia judaica do país, a Colônia Philippson, localizada em Itaara e que nos últimos anos resguarda uma herança que muito sofre pelo esquecimento e descaso. Em vista disso, o presente artigo pretende contribuir para a preservação da memória e identidade judaica recuperando a história e a cultura representada pelas tradições e elementos que compõe espaços sociais em Itaara e Santa Maria. Nesse sentido, entende-se que para preservar a memória de uma sociedade, é imprescindível manter as condições mínimas de sobrevivência, abrangidas, tanto no meio ambiente, quanto em seu saber.

Como metodologia realizou-se uma pesquisa bibliográfica, uma entrevista com o israelita Amiel Jairo e elaborou-se um inventário, onde propriedades são analisadas a partir de elementos que enriquecem a nossa história e memória. Conclui-se que o patrimônio é o resultado de um processo de construção social que para manter-se na memória da sociedade precisa ser preservado, lembrado, identificado e reconhecido por todos como parte da cultura local.

\section{Contexto histórico}


A presença de judeus no Brasil, remonta ao século XVII, decorrente de várias diásporas e exílios forçados em seus países de origem. Na região de Bessarábia (Polônia, Romênia e Ucrânia), na Rússia, atual Mondávia, russos de origem judaica conviviam de forma instável, sendo acuados conforme o governo que estivesse no poder. No entanto, os czares intolerantes a religião e línguas judaicas diferentes no país, promoveram perseguições aos judeus privandoos de sua liberdade. Tal situação culminou com a vinda dos semitas ao Brasil.

Cansados das perseguições religiosas, pogroms ${ }^{4}$ avassaladores, injustiças sofridas por discriminações religiosas e raciais, muitos judeus buscavam por melhores condições de vida, onde pudessem viver livres e em paz.Diante de tanta barbárie, houve a dispersão judaica pelo mundo e a paz tão buscada pelos judaicos seria encontrada no Brasil (AMIEL, 2014).

A abertura dos portos, em 1808 e a liberdade de religião obtida em 1889, atraíam povos perseguidos por sua opção religiosa, propiciando com isso a migração. Desta forma no início do século XX, a conjuntura política interna e externa ao Brasil possibilitava o fluxo de imigrantes.

Os primeiros imigrantes judeus que vieram de forma organizada para o Brasil receberam ajuda de uma associação de colonização judaica -Jewish Corporation Association, a I.C.Acriada em 1891 com intuito de transferir as famílias judias que sofriam com as perseguições por religião e raça, como também propiciar o desenvolvimento sociale econômico, no novo território, além de oferecer novas oportunidades de vida as famílias judias(GUTFREIND, 2010).

Por intermédio desta associação, e auxílio de Franz Philippson, banqueiro belga e diretor da Companhia Férrea de Santa Maria, no Rio Grande do Sul, propôs ao Conselho da ICA a aquisição de terras próximas a cidade para que fossem vendidas aos judeus sob forma de contrato, antes mesmo de suas vindas. Assim, em 1904, cerca de 38 famílias chegaram ao Brasil para habitar o que seria a primeira colônia judaica do país, a Colônia Philippson, onde receberam cerca de 25 a 30 hectares de terra por família, contendo uma casa de madeira, duas juntas de bois, duas vacas, um cavalo,suprimento em dinheiro e instrumentos de trabalho para desenvolverem atividades ligadas a agricultura (SANTOS, 2009).

O Brasil e, consequentemente, o estado gaúcho oferecia opções positivas para a vinda da comunidade judaica. Na medida em que outras repúblicas americanas restringiam

\footnotetext{
${ }^{4}$ Pogrom é uma palavra russa que designa um ataque, acompanhado por destruição, pilhagem de propriedade, assassinato e estupro, perpetrado por um segmento da população contra outra, principalmente os judeus. Esses ataques ocorreram durante períodos de grave crise política e estavam ligados a convulsões sociais e incitação nacionalista na Europa Oriental. Os judeus da Rússia foram vítimas de três ondas de pogroms: entre os anos de 1881 e 1884, 1903 e 1906, e 1917 e 1921.
} 
a imigração através de suas legislações, o Brasil, com suas imensas extensões de terras subpovoadas, centros urbanos em desenvolvimento, leis de imigração relativamente abertas e aparentemente ausência de anti-semitismo, parecia ser, de fato, o "país do futuro" (MEDIANEIRA, 2009, p.77)

Apesar de estarem satisfeitos com a nova vida no campo, ao se deslocarem para a cidade de Santa Maria a fim de comercializar seus produtos nas feiras, as famílias judias perceberam que a cidade em desenvolvimento com a viação férrea, oferecia mais possibilidades de crescimento para quem ali residia, o que as motivou a migrar para cidade.

Interessante e importante ressaltar que no momento em que o povo judeu se deslocou para o Brasil, passou a sofrer o processo de aculturação, um fenômeno de interação social que resulta do contato e troca entre culturas, originando mudanças importantes emambas (LARAIA, 2009).

Atualmente a comunidade israelita de Santa Maria-RS abarca os seguintes bens patrimoniais na cidade:

- $\quad$ Fazenda Philippson;

- $\quad$ Cemitério Israelita de Philippson;

- $\quad$ Monumento ao Imigrante Judeu;

- $\quad$ Cemitério Chácara das Flores;

- $\quad$ Sinagoga Yitzhak Rabin.

Cabe salientar que tanto a fazenda Philippson, quanto o cemitério são remanescentes da Colônia Philippson, um somatório de glebas adquiridos pela I.C.A, dos quais foram divididos e distribuídos para as famílias que vieram residir no Rio Grande do Sul. Constituíam a colônia, casas, escola, núcleos comerciais, estação férrea e sinagogae destes somente a fazenda e o cemitério resistiram ao tempo.

Abaixo cada propriedade será analisada em forma de inventário, a fim de estudar e enriquecer a nossa história e resguardar essa cultura que sofre com o descaso.

Os bens são agrupados por categoria e registrados em livros que compõe o Livro dos Registros, instituído pelo IPHAN para o Plano Nacional, onde acreditamos que os bens considerados integram o Livro das Celebrações e dos Lugares.

\section{Inventário de identificação de bens, $n^{0}: 1$.}

- Denominação:Fazenda Philippson

- Localização/município:As margens da BR 158- Itaara- RS, na época $6^{\circ}$ Distrito do Município de Santa Maria.

- Época de construção:18 de outubro de 1904, 5665 para os judeus. 
- Estado de conservação/ grau de caracterização:

Algumas residências ainda permanecem no local, porém suas características originais sofreram alterações ao longo dos anos.Persiste o que é considerado a "casa grande" e outras duas residências menores, todas em madeira,ocupadas porcaseiros que cuidam o espaço.

Sua entrada é marcada por um monumento em homenagem aos imigrantes judeus e um "pórtico" com a nomeação da fazenda.

- Uso original e uso atual: Lote de terra destinada a exploração agrícola pertencente à Colônia Philippson. Atualmente permanece uma fazenda com a mesma função, porém somado a criação de gado.

- Categoria: Patrimônio arquitetônico e cultural.

- Proteção existente: Nenhuma.

- Propriedade: Particular- Pertence a Cláudio Benjamim Steinbruch e Alegria Steinbruch.

- Informações históricas:

A Fazenda Philippson, teve início em 1904 com primeiro dono Abraão Philippson. Este era o lote $\mathrm{n}^{\mathrm{o}} 16$ dos47 que formavam a Colônia Philippson. O centro da fazenda preserva oprimeiro cemitério judaico do Brasil.

- Informações complementares:

A área de Philippson teve a linha férrea como um elemento propulsor e dinamizador da colônia, sendo que a Fazenda Philippson ficava as margens dessa linha. Na configuraçãoatual, existe a inserção da rodovia federal, BR 158, que se alinha paralelamente à linhaférrea. Este trecho é o responsável por realizar a ligação entre o Município de SantaMaria ao Município de Cruz Alta.

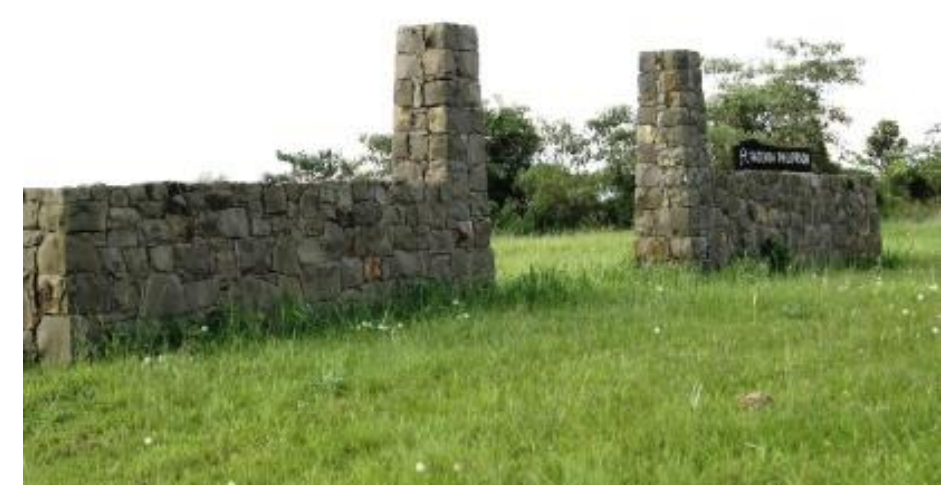

Fotografia 1 - Fazenda Philippson

Fonte: Acervo das autoras (2016) 
RELACult - Revista Latino-Americana de Estudos em Cultura e Sociedade

Revista Latinoamericana de Estudios en Cultura y Sociedad | Latin American Journal of Studies in Culture and Society V. 05, ed. especial, abr., 2019, artigo n ${ }^{\circ} 1242$ | claec.org/relacult |e-ISSN: 2525-7870

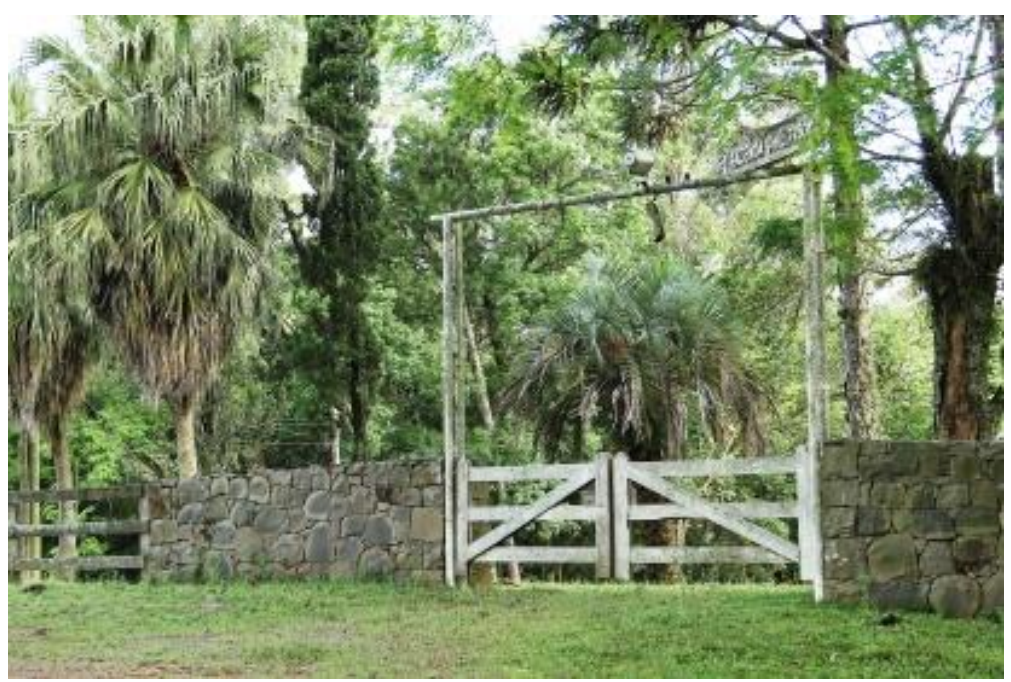

Fotografia 2 - Fazenda Philippson

Fonte: Acervo das autoras (2016)

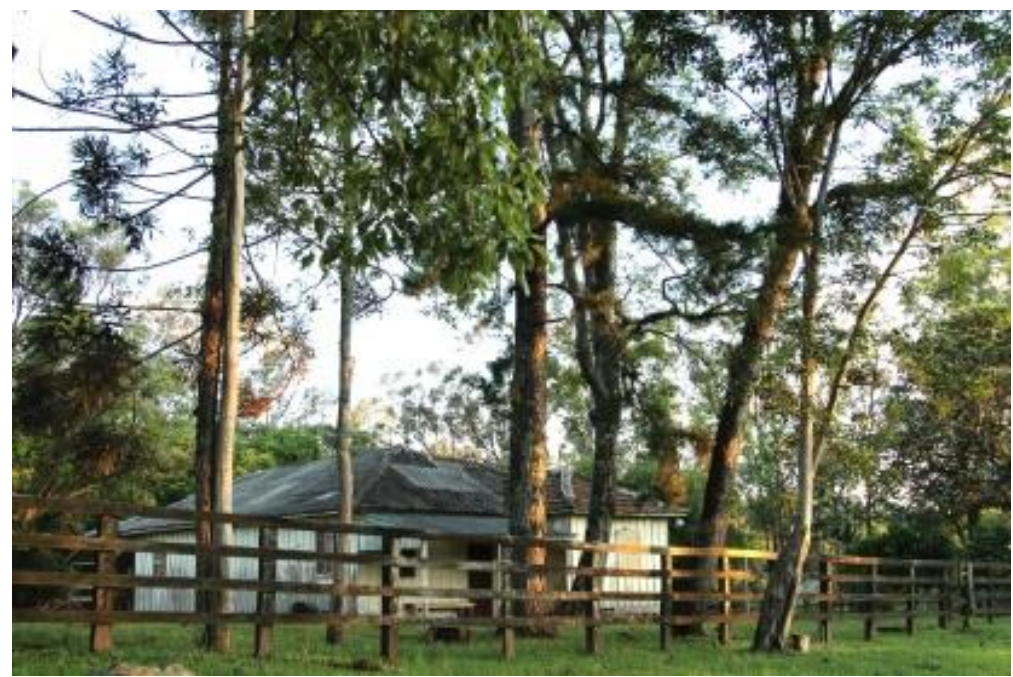

Fotografia 3 - Fazenda Philippson

Fonte: Acervo das autoras (2016)

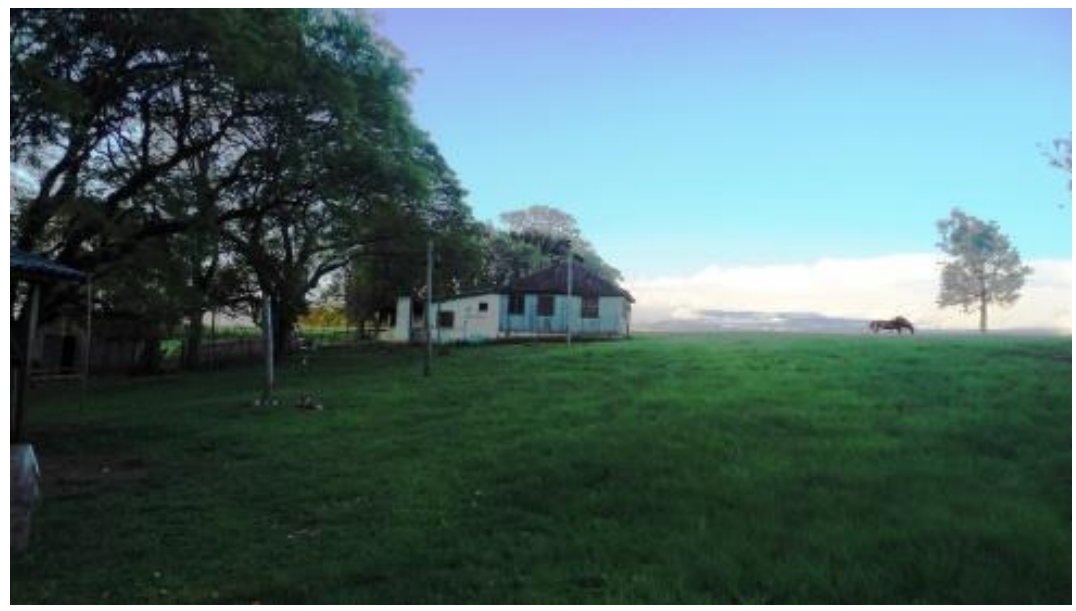

Fotografia 4 - Fazenda Philippson

Fonte: Acervo das autoras (2016) 


\section{Inventário de identificação de bens, $n^{0}: 2$.}

- Denominação: Cemitério Israelita de Philippson.

- Localização/município:Localiza-se junto a Fazenda Philippson, próximo a BR 158Itaara-RS.

- Época de construção e desativação aproximada: 1904- 1924

- Estado de conservação/ grau de caracterização:

O cemitério encontra-se em situação de abandono e bastante deteriorado. No chão, o revestimento em pedra basalto está encoberto por mato e ervas daninhas que crescem livremente no local amparando uma variedade de insetos. Muitos dos jazigos estão assolados, quebrados, com as tampas abertas e até mesmo com plantas se desenvolvendo nos seus interiores, espaço onde deveriam estar repousando as ossaturas dos primeiros imigrantes judeus.Parte do muro de pedra que cerca o local está desmanchando, e a capela que serve de pórtico e local de orações, apresenta telhas quebradas na cobertura, muita sujeira e sinais de umidade.

- Intervenções: Reforma em 1979 e 1997.

- Uso original e uso atual: Espaço utilizado para guardar os corpos dos descendentes semitas. Hoje, o espaço é tombado como patrimônio do estado e é "preservado" para visitações.

- Categoria: Patrimônio arquitetônico, histórico e religioso.

- Proteção existente: Portaria nº 36/94, tombamento pela Secretaria de Estado da Cultura do Rio Grande do Sul em 1994.

- Propriedade: Público- Estado do Rio Grande do Sul.

- Informações históricas:

Patrimônio das famílias que participaram do primeiro grupo de colonos judeus vindos da região de Bessarábia, por motivos de perseguições religiosas.

O campo sagrado é o primeiro cemitério judaico do Brasil, e se localiza no centro da Fazenda Philippson. Este é um elemento cultural significativo que representa a concretização da existência do grupo cultural judaico, nos entornos de Santa Maria. É testemunha material como um bem arquitetônico permanente, considerado um lugar dotado de forte contexto histórico e cultural.

Em 1979, o cemitério passou por uma reforma e recebeu uma homenagem na forma de uma placa comemorativa, onde se lê "Aos imigrantes que nos legaram a fé inquebrantável e uma terra de paz e liberdade, homenagem de seus descendentes e da comunidade israelita do rio grande do sul- Philippson outubro de 1979” e em 1997 recebeu uma última manutenção. 
- Informações complementares:

O cemitério Israelita de Philippson guarda 80 unidades de túmulos e possui uma área de $1.294,39 \mathrm{~m}^{2}$ com aproximadamente $30 \times 34$ e 40X41m de dimensões. O espaço do cemitério é visivelmente dividido em três aglomerações, a direita para o sepultamento dos homens, a esquerda para as mulheres e os fundos, destinado para as crianças.

As sepulturas apresentam a estrela de David na sua frente que representa proteção ao povo. As lápides estão voltadas para o oeste, de modo que as pessoas ali sepultadas estão com a cabeça voltada para o ocidente, posição do sol nascente, assim como também, para a terra prometida, Israel (BERGER, 2004).

Em 21 de novembro de 2014, terá início uma restauração que prevê a consolidação e reparo dos muros do cemitério; adequação do portal de entrada; retirada das pedras do calçamento atual; reintrodução de grama; instalação de novos passeios de pedras; drenagem do terreno; consolidação e limpeza dos túmulos; instalação de bancada com mapeamento dos mesmos e restauração das ornamentações existentes em algumas sepulturas. As obras estruturais devem iniciar em janeiro e ter duração de seis meses (VASCONCELLOS, 2014).

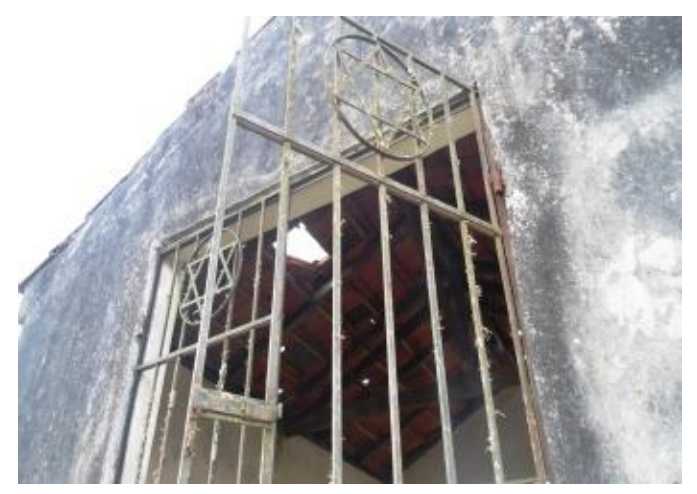

Fotografia 5 - Capela de entrada do Cemitério de Philippson Fonte: Acervo das autoras (2016)

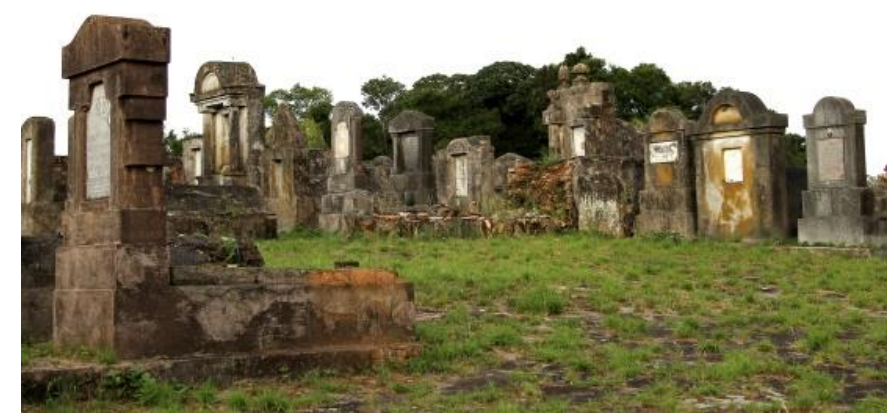

Fotografia 6 - Cemitério de Philippson Fonte: Acervo das autoras (2016) 
RELACult - Revista Latino-Americana de Estudos em Cultura e Sociedade

Revista Latinoamericana de Estudios en Cultura y Sociedad | Latin American Journal of Studies in Culture and Society V. 05, ed. especial, abr., 2019, artigo n ${ }^{\circ} 1242$ | claec.org/relacult | e-ISSN: 2525-7870

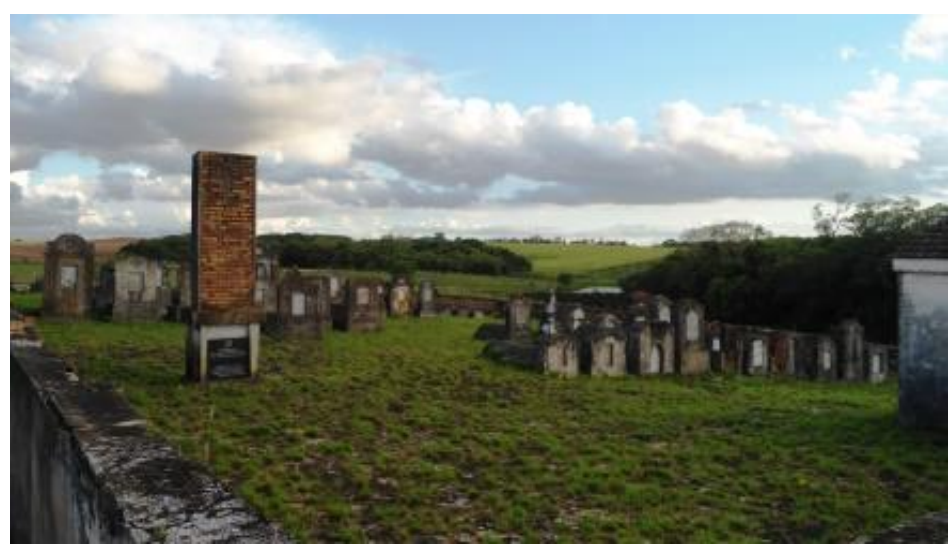

Fotografia 7 - Cemitério de Philippson Fonte: Acervo das autoras (2016)

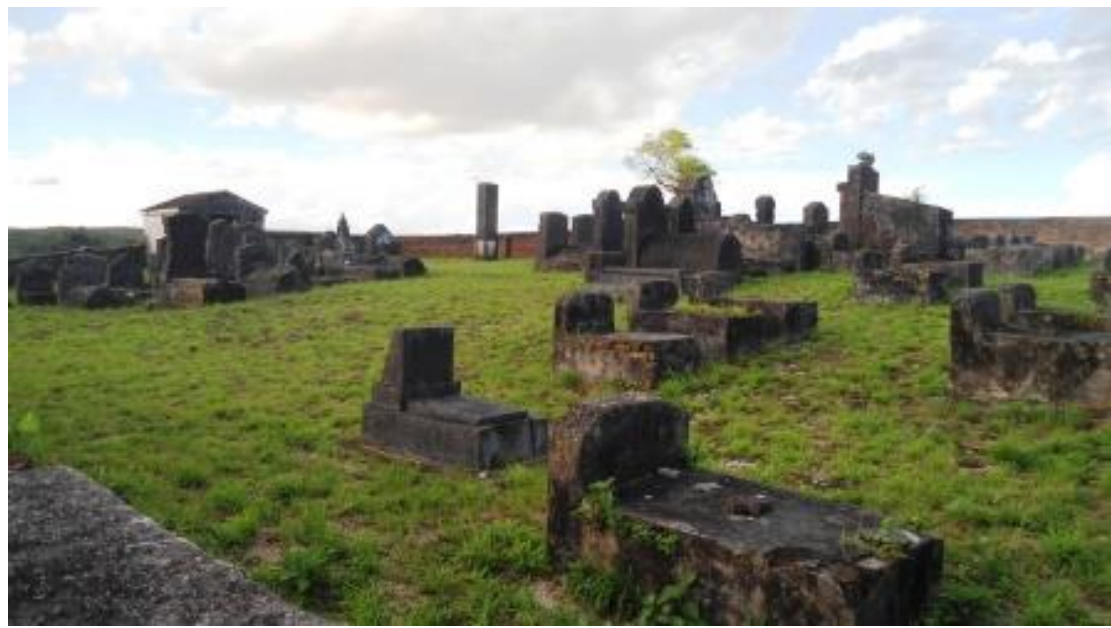

Fotografia 8 - Cemitério de Philippson

Fonte: Acervo das autoras (2016)

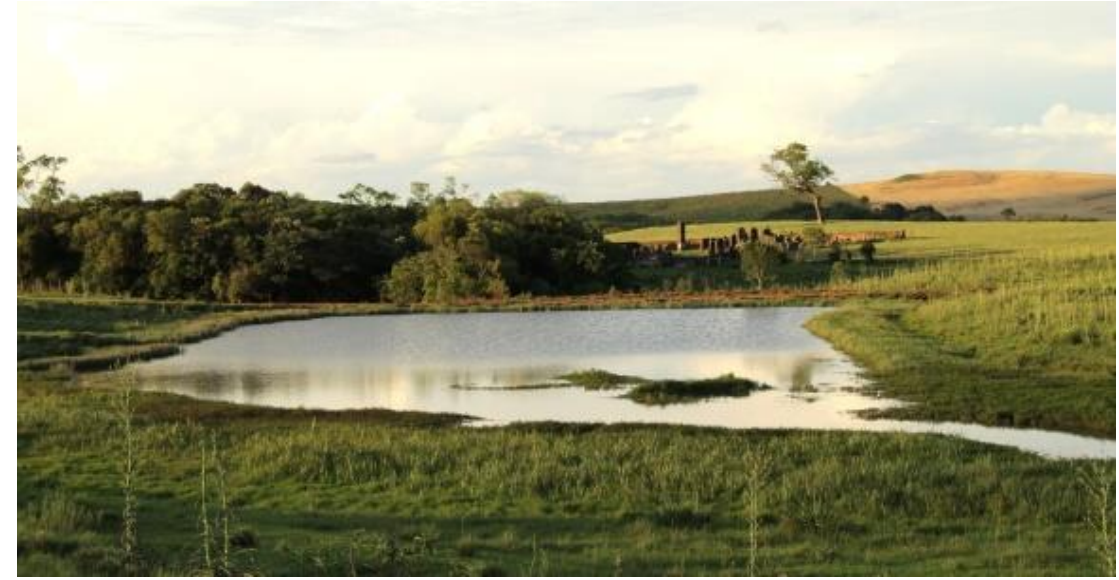

Fotografia 9 - Campo que dá acesso ao Cemitério de Philippson

Fonte: Acervo das autoras (2016)

\section{Inventário de identificação de bens, $n^{0}: 3$.}

- Denominação: Monumento ao Imigrante Judeu. 
- Localização/município: BR 158, Itaara- RS.

- Época de construção:1997.

- Estado de conservação/ grau de caracterização:

O monumento se encontra bem conservado e fica as margens da BR 158 convidando e dando boas vindas às pessoas que queiram conhecer o que sobrou da Fazenda Philippson e do cemitério no seu interior.

- Uso original e uso atual: Marco histórico.

- Categoria: Monumento histórico.

- Proteção existente: Nenhum.

- Propriedade: Público.

- Informações históricas:

Marco histórico-cultural da primeira colonização judaica no Brasil ente 1904 e 1916.

- Informações complementares:

$\mathrm{O}$ monumento apresenta na lateral principal que esta de frente para a $\mathrm{BR}$, na parte superior uma roda com a estrela de David, abaixo vem os dias da semana com uma marcação no sábado, dia da semana que é guardado pelos judeus - o shabat - depois a tábua dos mandamentos e na parte inferior, frases em cada lateral do monumento.

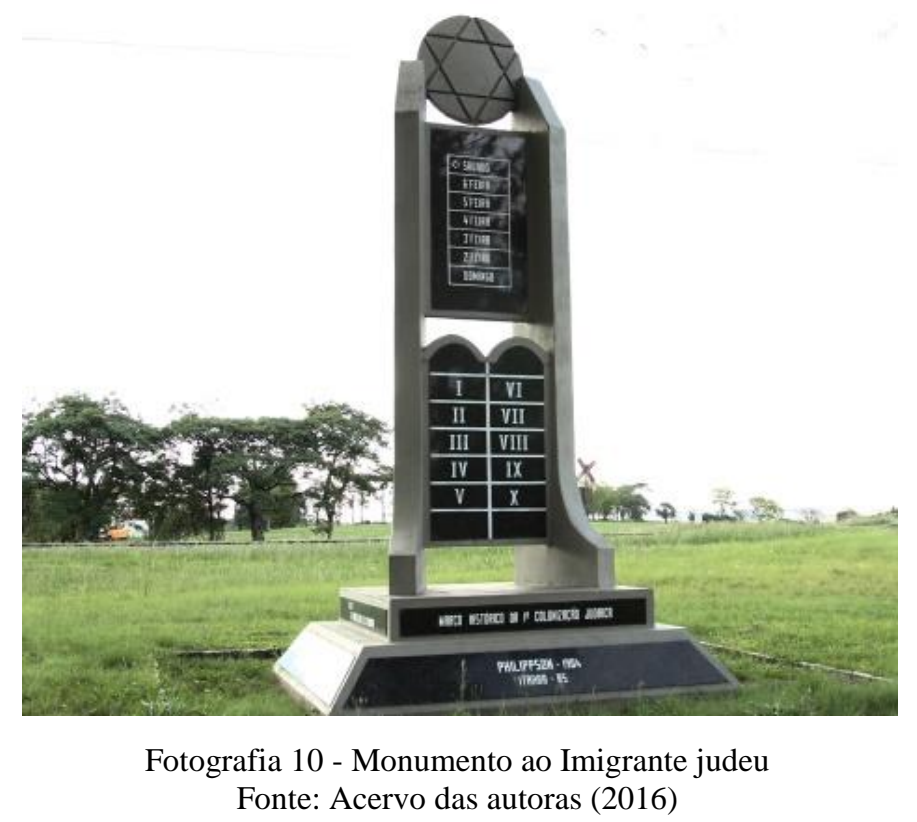

\section{Inventário de identificação de bens, $n^{0}: 4$.}

- Denominação: Cemitério Chácara das Flores. 
- Localização/município: Travessa Clara Steinbruch, Bairro Chácara das Flores- Santa Maria- RS.

- Ano de construção: 1924.

- Estado de conservação/ grau de caracterização:

Alguns túmulos se apresentam quebrados, outros com afundamento no solo, alguns retratos na frente dos mesmos estão fragmentos ou sem as imagens. Parte do calçamento ao redor dos jazigos exibem falhas das peças, os paralelepípedos das ruelas são irregulares com gramíneas crescentes entre seus encaixes, enquanto que boa parte do terreno é coberta por grama. Porém, de forma geral, o cemitérios e encontra em razoável estado de conservação.

- Uso original e uso atual: Ambos para guardar os restos letíferos dos integrantes da sociedade judaica da cidade de Santa Maria- RS.

- Categoria: Patrimônio arquitetônico, histórico e religioso.

- Proteção existente: Nenhuma.

- Propriedade: Sociedade Beneficente Israelita de Santa Maria.

- Informações históricas:

Com as dificuldades enfrentadas pelos imigrantes que viviam no interior de Itaara e região, o Cemitério Israelita da Chácara das Flores foi construído em 1924 para as famílias judias que vinham se estabelecer na cidade de Santa Maria. Assim, paralelamente o Cemitério da colônia Philippsonfoi desativado.

- Informações complementares:

Neste cemitério existem 245 túmulos e assim como no de Philippson, o lado direito guarda os homens, na lateral esquerda, as mulheres e ao fundo, as crianças. Conforme conversa com Jair Jardim (cuidador do cemitério), no início, os judeus considerados impuros (casados com outras etnias), assim como os suicidas eram sepultados no mesmo terreno, porém separados daqueles considerados "puros".

O cemitério possui uma área $3.154 \mathrm{~m}^{2}$ com dimensões de aproximadamente $43 \times 37 \mathrm{e}$ 80x78m. Diferentemente do Cemitério de Philippson, algumas sepulturas possuem a lápide voltada para o leste e presença de flores. Em quase todas existe uma estrela de seis pontas, um hexagrama, algumas vezes entrelaçadas, outras não. Segundo Berger (2004) a estrela de seis pontas entrelaçadas estaria relacionada com a Maçonaria, porém, em entrevista com a $\mathrm{Sr}^{\text {a }}$ Teresa Seligmam, a autora conclui que as estrelas tenham sido desenhadas sem esse conhecimento, ou seja, sem ligação com a Maçonaria.

Os judeus costumam visitar o cemitério entre RoshHashaná- Ano Novo Judaico que é comemorado por dois dias, quando se dá início aos dez dias de arrependimento ou exame da 
alma que termina no YomKipu r- Dia do Perdão. Nesse dia são perdoados os pecados contra Deus.

Ao visitarem uma sepultura, os judeus no lugar de flores costumam deixar pedras sob a lápide, pois para eles, as pedras são usadas para marcar a visita daquela pessoa ao túmulo de seu parente, visto que estas não seriam levadas pelo vento, além de simbolizar os obstáculos pelos quais todos passam durante a vida e que precisam ser superados, entre eles a morte (BERGER, 2004).

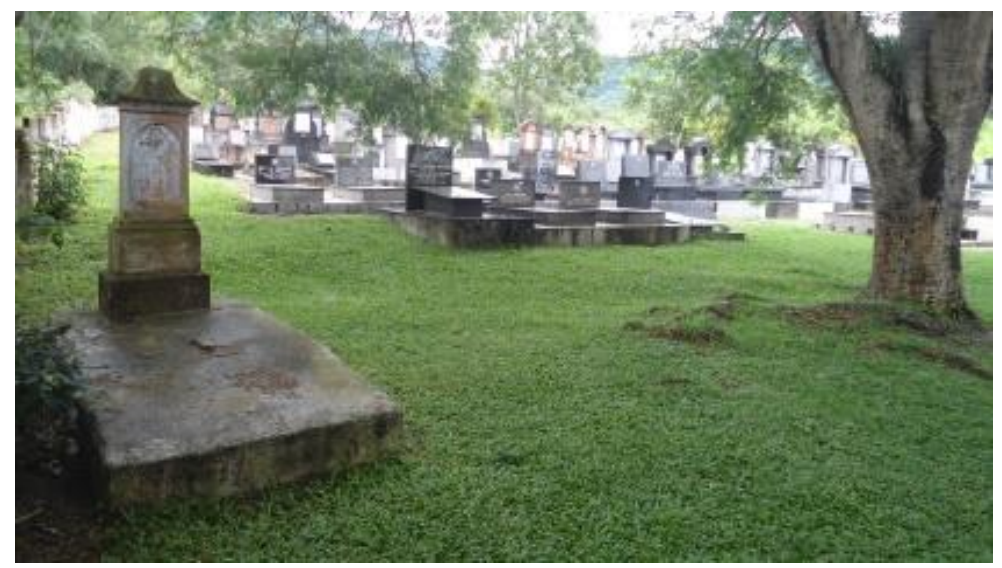

Fotografia 11 - Cemitério Chácara das Flores Fonte: Acervo das autoras (2016)

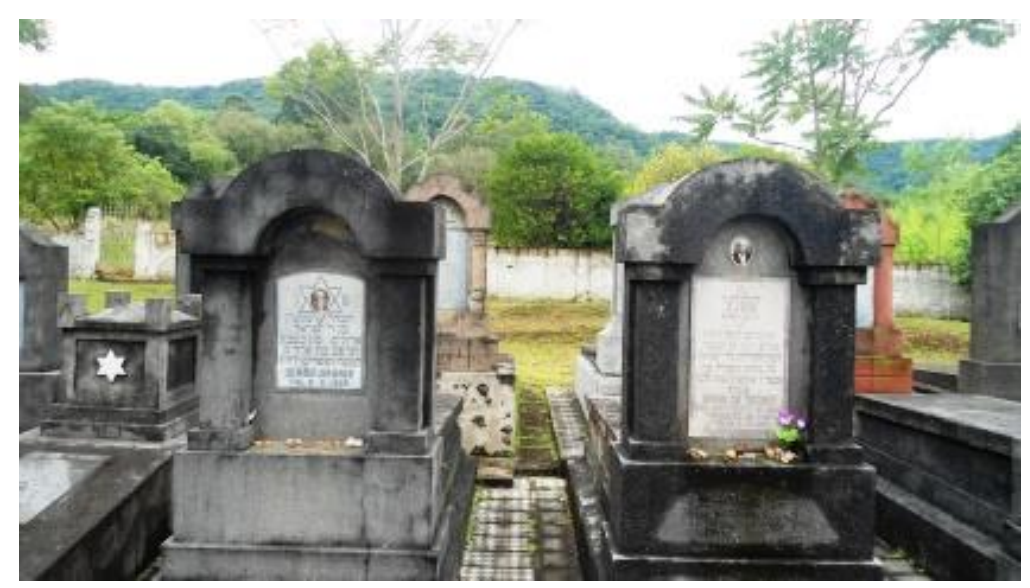

Fotografia 12 - Cemitério Chácara das Flores

Fonte: Acervo das autoras (2016) 


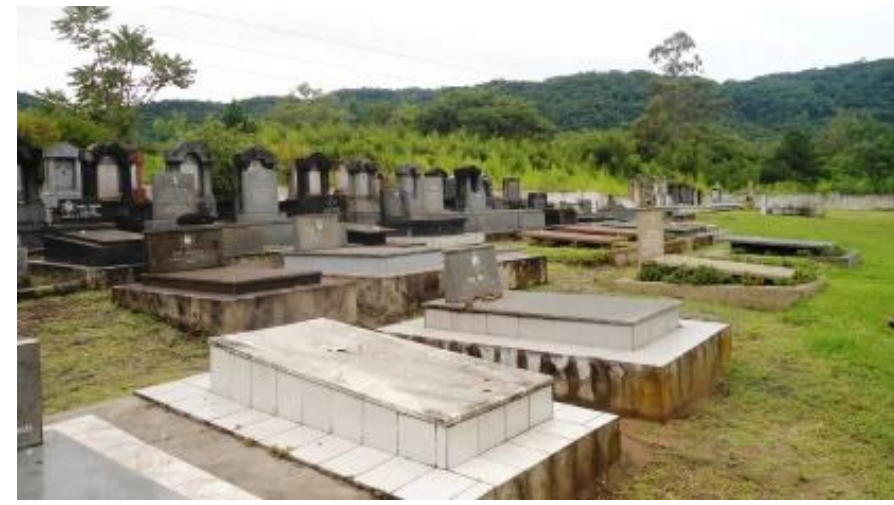

Fotografia 13 - Cemitério Chácara das Flores Fonte: Acervo das autoras (2016)

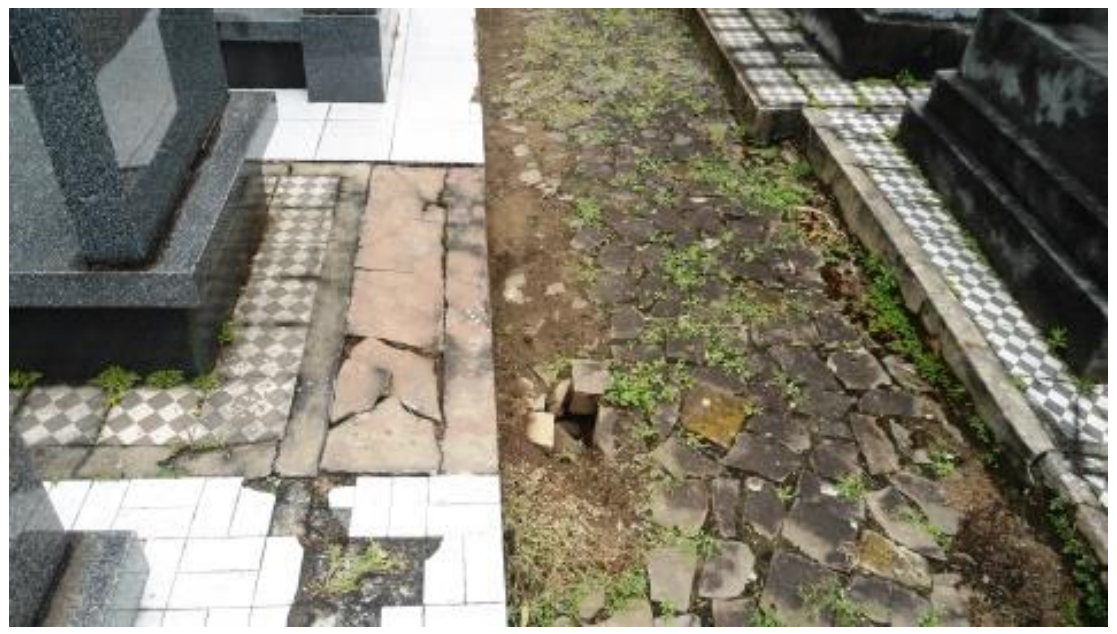

Fotografia 14 - Cemitério Chácara das Flores Fonte: Acervo das autoras (2016)

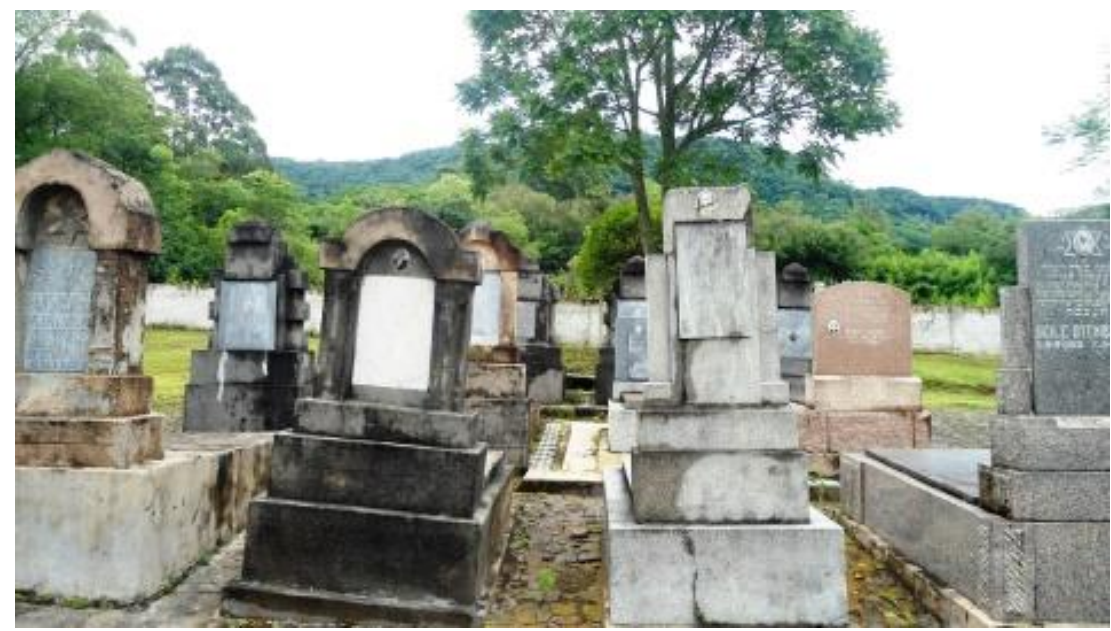

Fotografia 15 - Cemitério Chácara das Flores

Fonte: Acervo das autoras (2016)

\section{Inventário de identificação de bens, $n^{0} 5$.}

- Denominação: Sinagoga Yitzhak Rabin. 
- Localização/município: Rua Otávio Binato, n49, Bairro: centro - Santa Maria/RS.

- Época de construção: 1923

- Estado de conservação/ grau de caracterização:

Bem conservada. Projetada por imigrantes judeus que vieram para a cidade, moradores da Colônia Philippson.

- Uso original e uso atual:

O templo serve para atividades religiosas. Proferem nas sextas-feiras o Cabalat Shabat. Nesse espaço religioso os homens judeus usam a Kippa, pequena touca, que representa o respeito a Deus no momento de orações.

Shabat é o nome dado ao dia de descanso semanal, simbolizando o sétimo dia em Gênesis, a partir do pôr-do-sol de sexta-feira até o pôr-do-sol de sábado, o exato momento de início e final do Shabat.

- Intervenções: Reforma em 1997.

- Categoria: Patrimônio arquitetônico e religioso.

- Proteção existente: Lei no 4615 de 29 de outubro de 2002, onde considera patrimônio histórico do município de Santa Maria o prédio do templo da Sinagoga localizada na Rua Otávio Binato, $\mathrm{n}^{\circ} 49$.

- Propriedade: Comunidade Judaica.

- Informações históricas:

O comércio de Santa Maria por volta do ano de 1918-1919 era bastante precário. Diante dessa realidade, logo os colonos judeus perceberam a necessidade de ampliá-lo como também a perspectiva de inserir seus ofícios mercantis desempenhados em seu país de origem. Com essa visão, passaram a migrar para as zonas urbanas, e como nessa área não existia um espaço voltado para sua religião, em $1^{\circ}$ de janeiro de 1919 foi fundado a Sociedade Beneficente Israelita de Santa Maria. A Sinagoga como conhecemos hoje foi edificada, em 1923, a partir da união de recursos dos membros dessa Sociedade e da necessidade por um espaço para suas orações. Esta foi a $1^{a}$ Sinagoga a ser construída no Rio Grande do Sul.

- Informações complementares:

Sua arquitetura se apresenta em estilo românico e teve influência das construções trazidas pelos imigrantes, ressaltando elementos geométricos e a simetria da fachada onde aparece as Tábuas dos Dez Mandamentos, um dos símbolos sagrados da religião judaica. No interior da Sinagoga ocorriam as cerimônias religiosas, onde antigamente os homens ficavam na parte inferior do salão, enquanto os mezaninos eram ocupados por mulheres e crianças. Nesse espaço procuram manter as tradições religiosas de seus antepassados. 
No interior da Sinagoga são encontrados símbolos da religiosidade judaica, tais como: a Arca e o Memorá. A arca representa a ligação entre Deus e o Povo Judeu, uma espécie de caixa onde são guardados os pergaminhos sagrados da Torá, livro sagrado que foi revelado diretamente por Deus e o Memorá, candelabro sagrado com sete braços.

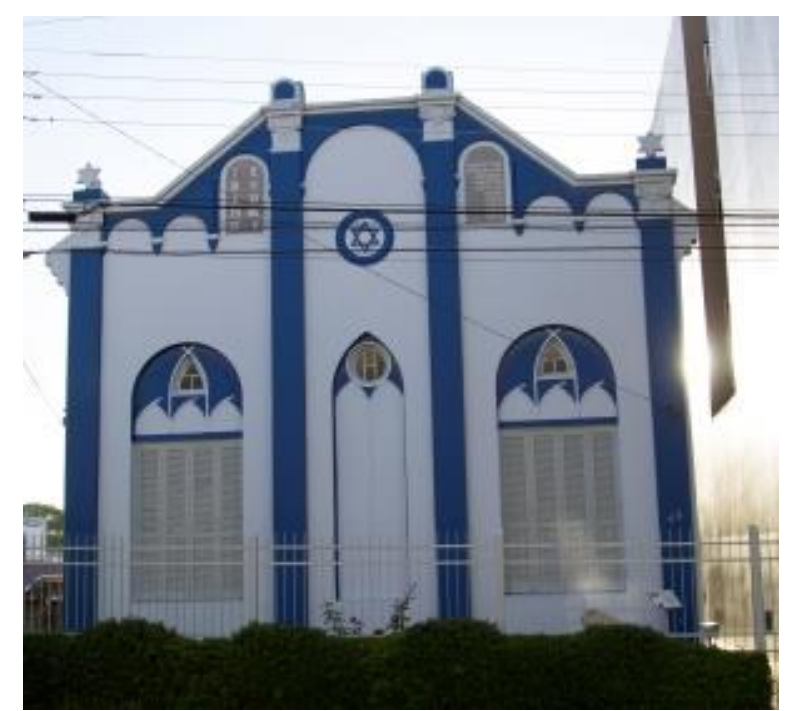

Fotografia 16 - Sinagoga Yitzhak Rabin Fonte: Acervo das autoras (2016)

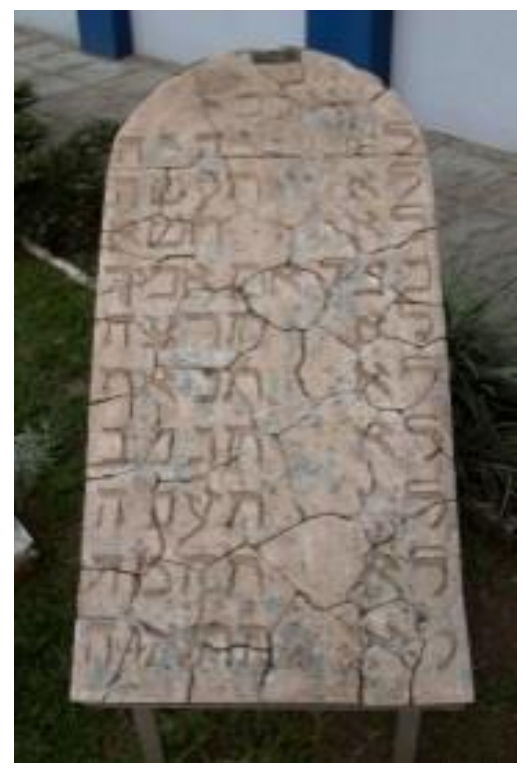

Fotografia 17 - Sinagoga Yitzhak Rabin Fonte: Acervo das autoras (2016) 
RELACult - Revista Latino-Americana de Estudos em Cultura e Sociedade

Revista Latinoamericana de Estudios en Cultura y Sociedad | Latin American Journal of Studies in Culture and Society V. 05, ed. especial, abr., 2019, artigo n ${ }^{\circ} 1242$ | claec.org/relacult | e-ISSN: 2525-7870

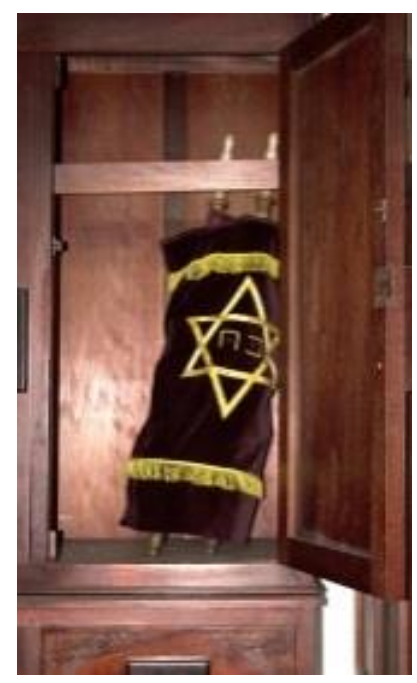

Fotografia 18 - Sinagoga Yitzhak Rabin Fonte: Acervo das autoras (2016)

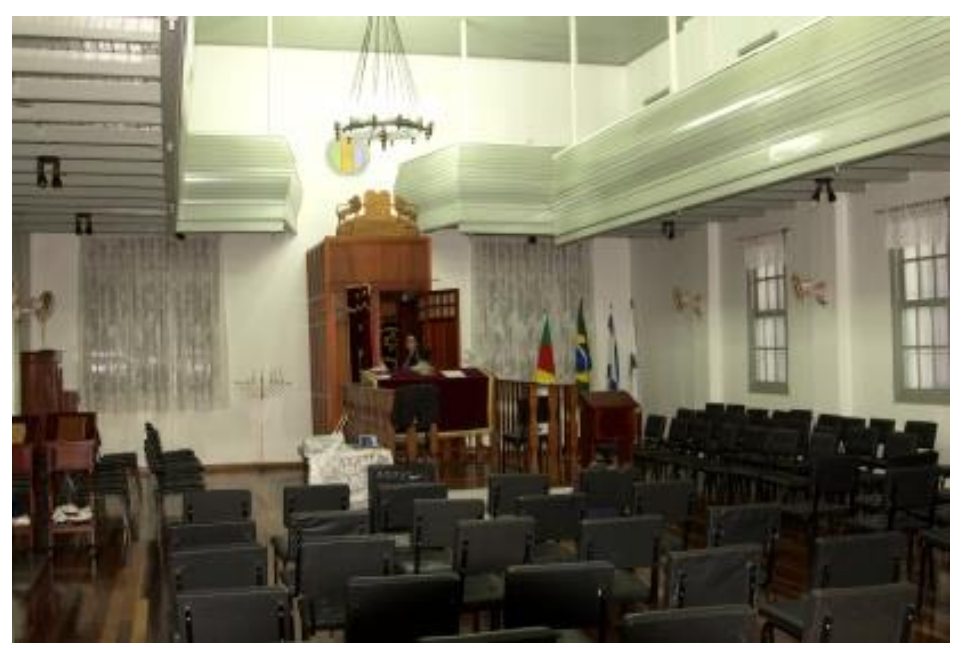

Fotografia 19 - Sinagoga Yitzhak Rabin Fonte: Acervo das autoras (2016)

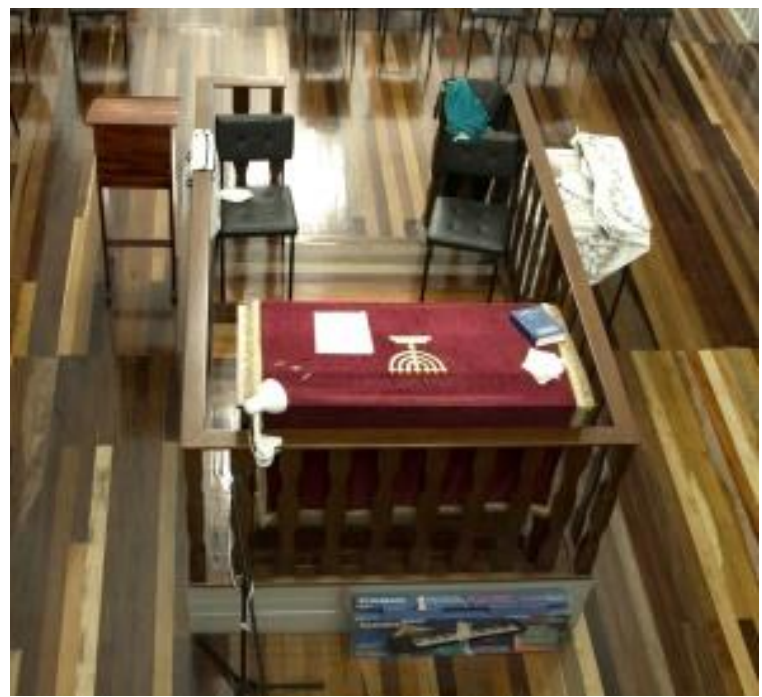

Fotografia 20 - Sinagoga Yitzhak Rabin

Fonte: Acervo das autoras (2016) 


\section{Considerações finais}

A escolha em inventariar as propriedades acima, se deve a importância em resgatar a história e a cultura representada nas tradições e elementos que compunham os espaços sociais, de modo a contribuir para a preservação da memória e da identidade judaica na cidade de Santa Maria. Porém, para preservar as características de uma sociedade, é imprescindível manter as condições mínimas de sobrevivência, abrangidas tanto no meio ambiente quanto no seu saber. Segundo Lemos (1987), os elementos componentes do patrimônio material e os não tangíveis ligados ao conhecimento especialmente as tradições deveriam ter prioridade no processo preservacionista.

Para tanto, a educação tem um papel preponderante na preservação de elementos que compõe a cultura de um espaço, ao transmitir hábitos e costumes que irão resistir a passagem do tempo e mudanças inseridas pela modernidade. Os rituais religiosos ocorridos na sinagoga são um exemplo de como esta cultura se mantém viva ainda hoje e graças ao legado repassado de pai para filho ainda persiste. Dessa maneira, o conhecer, o fazer e o admirar são intrínsecos ao ato de identificar, preservar e valorizar para que a cultura torne-se um legado do patrimônio histórico, destacando sua importância material como representante estético de diferentes épocas, e imaterial em referência aos rituais religiosos, hábitos e costumes.

Choay (2001) assevera que um patrimônio faz parte da vida do lugar, mantém uma relação com todo seu entorno e a população local. A partir dessa afirmação, cabe analisarmos se os bens patrimoniais da cidade estão inseridos ativamente na sociedade a qual pertence e que o tem como um patrimônio tombado. Em vista dessa cultura, a sociedade de Santa Maria identifica que a cultura semita foi berço de sua colonização no estado? A cidade reconhece seu legado como patrimônio histórico e social?

O Cemitério de Philipppson, apesar de ser tombado pelo Instituto do Patrimônio Histórico e Artístico do Estado do Rio Grande do Sul (IPHAE), encontra-se abandonado e a falta de acessibilidade no local certamente é um empecilho à visitação, acarretando certo desconhecimento até mesmo pela população local.

Assim, a busca pela origem é de suma importância para a constituição de uma sociedade consciente de suas raízes e de sua identidade. Portanto conclui-se que o patrimônio é o resultado de um processo de construção histórica e social que para manter-se na memória da sociedade precisa ser preservado, lembrado, identificado e conhecido por todos a fim de ser valorizado e inserido na sociedade como parte da cultura local. 


\section{Referências}

AMIEL, Jairo. Judeus em Santa Maria. Santa Maria, 11 nov.2014. Entrevista concedida a Marcele Cortes, Márcia Cortes e Micheli Lopes.

BERGER, Rejane de Fatima Devicari, A arquitetura cemiterial israelita de Philippson no processo de criação de Design de Superfície através do mosaico, RS, 2004. (Especialização em Design para Estamparia). Santa Maria/RS: Universidade Federal de Santa Maria - UFSM, 2004.

CONFEDERAÇÃO ISRAELITA DO BRASIL. História dos judeus no Brasil. Disponível em: <http://www.conib.org.br/historia>. Acesso em: 01 nov. 2014.

FEDERAÇÃO ISRAELITA DO RIO GRANDE DO SUL.Patrimônio histórico do RS, cemitério de Philippson será restaurado. Disponível em: < http://firs.org.br/multimidia/noticia/patrimonio-historico-do-rs-cemiterio-de-philippson-serarestaurado>. Acesso em: 17 nov. 2014.

Gritti, Isabel Rosa, Imigração judaica no Rio Grande do Sul : a Jewish Colonization Association e a colonização de Quatro Irmãos. Porto Alegre: Martins Livreiro, 1997.

Gutfreind, Ieda. Comunidades judaicas no interior do RS : Santa Maria. Santa Maria: UFSM, 2010. 152 p.

Laraia, Roque de Barros. Cultura: um conceito antropológico.23. ed. Rio de Janeiro, RJ: J. Zahar, 2009. $117 \mathrm{p}$.

Ritzel, Ricardo Agne. Fazenda Phillipson: os 110 anos da imigração judaica em Santa Maria. Disponível em: <http://www.apusm.com.br/2014/09/fazenda-phillipson-os-114-anos-daimigracao-judaica-em-santa-maria/>. Acesso em: 17 nov. 2014.

Santos, Maria Medianeira dos. A territorialidade judaica em Santa Maria/RS: uma contribuição a geografia cultural. Santa Maria, 2009.

Sinagogas do Brasil. 2. ed. São Paulo, SP : Banco Safra, 2010.

SOCIEDADE BENEFICENTE ISRAELITA SANTA MARIA. Disponível em: <http://www.sbism.com.br/>. Acesso em: 18 nov. 2014.

THE LIBRARY. Modern Jewish history: Progroms. Disponível em: $<$ http://www.jewishvirtuallibrary.org/jsource/History/pogroms.html >. Acesso em: 01 nov. 2014.

VASCONCELLOS, Manuela. Governo do Estado confirma reforma do Cemitério Philippson, em Itaara. Diário de Santa Maria, Santa Maria, 21 nov. 2014. Disponível em: $<$ http://diariodesantamaria.clicrbs.com.br/rs/geral-policia/noticia/2014/11/governo-do-estadoconfirma-reforma-do-cemiterio-philippson-em-itaara-4647598.html>. Acesso em: 02 dez.2014. 